\title{
Self-induced vomiting and bulimia nervosa: an undetected problem
}

\author{
CHRISTOPHER G FAIRBURN, PETER J COOPER
}

\begin{abstract}
Six hundred and twenty women who were currently practising self-induced vomiting to control their weight were identified with the help of a women's magazine. Nineteen women (3.1\%) fulfilled diagnostic criteria for anorexia nervosa. Of the remainder, $499(83.0 \%)$ fulfilled diagnostic criteria for bulimia nervosa, a recently described eating disorder. Of these, $56.1 \%$ practised self-induced vomiting at least once daily; the mean duration of vomiting was 4.5 years. Most women were of normal body weight. On standardised measures, 68.1\% of women showed pronounced psychiatric morbidity and $89 \%$ had profoundly disturbed attitudes to food and eating. $56.4 \%$ thought they definitely needed medical help, though only $30 \cdot 1 \%$ had ever discussed any aspect of their eating difficulties with a doctor.

This study highlights the secrecy that surrounds bulimia nervosa and suggests that it is an important undetected source of psychiatric morbidity.
\end{abstract}

\section{Introduction}

Self-induced vomiting as a means of weight control is well recognised in anorexia nervosa. It is also a feature of the recently described eating disorder bulimia nervosa. ${ }^{1}$ This syndrome has three diagnostic criteria: the patients have powerful and intractable urges to overeat; they seek to avoid the "fattening" effects of food by induced vomiting or abusing purgatives or both; and they have a morbid fear of becoming fat. The condition has a notable physical and psychological morbidity. ${ }^{1-3}$

University Departments of Psychiatry, Warneford Hospital, Oxford, and Royal Edinburgh Hospital, Edinburgh

CHRISTOPHER G FAIRBURN, MPHIL, MRCPSYCH, research psychiatrist (present address: University Department of Psychiatry, Warneford Hospital, Oxford OX3 7JX)

University Department of Psychiatry, Warneford Hospital, Oxford OX3 7JH

PETER J COOPER, DPHIL, research fellow
The prevalence of bulimia nervosa is not known. It is likely that cases will escape detection by conventional epidemiological methods because extreme guilt and secrecy surround the bouts of uncontrolled eating (binge-eating) and self-induced vomiting. Furthermore, friends and relatives of the patients would be of limited value in detecting cases, since individuals' shape and weight are usually normal and their eating habits in social circumstances may be unremarkable. ${ }^{2}{ }^{4}$

This study was designed to identify a community sample of individuals who were using self-induced vomiting as a means of weight control; to determine which of them satisfied diagnostic criteria for bulimia nervosa, to describe the characteristics of the condition, and to establish how many cases had previously been undetected although the individuals wanted treatment. The only cases of bulimia nervosa previously described were in patients attending psychiatric hospitals.

\section{Subjects and methods}

A notice was placed in the health reports page of a popular women's magazine in April 1980 requesting people who were using selfinduced vomiting as a means of weight control to write to the first author if they were prepared to complete a confidential questionnaire. Vomiting was chosen as the index feature for identifying a potential sample with bulimia nervosa, as it is the most easily defined of the three elements of the condition; a relative evaluation is required in defining gross overeating, ${ }^{5}$ and what constitutes a morbid fear of fatness is not clear.

Over 1000 replies to this request were received. The first 800 were sent a 170-item questionnaire designed to elicit information on weight, eating attitudes, and behaviour. Two reputable selfadministered psychometric instruments were also included: the scaled version of the General Health Questionnaire ${ }^{8}$ designed to detect patients with probable psychiatric disorder; and the Eating Attitude Test, ${ }^{7}$ which assesses a broad range of attitudes and behaviour characteristic of patients with anorexia nervosa.

\section{Results}

Of the 800 questionnaires sent out, $669(83.6 \%)$ were returned satisfactorily completed. To identify those with bulimia nervosa two groups were excluded: those who were not currently vomiting 
$(n=49)$ and those $(n=19)$ who fulfilled diagnostic criteria for anorexia nervosa derived from those of Russell. 8 These were a body weight of less than $85 \%$ of the matched population mean weight (expressed as a percentage of the average weight for age, height, and $\operatorname{sex}^{9}$ ) as a result of self-induced weight loss, amenorrhoea of at least six months' duration, and a morbid fear of fatness. The latter was judged to be present if there was a positive response to the question on the Eating Attitudes Test concerning being "terrified about being overweight." Since establishing this psychopathology on the basis of a single response to a question on the test might have been an oversimplification, further checks were made. Firstly, $95 \%$ of these individuals had responded affirmatively to the two other test questions relating to "a morbid fear of fatness"-namely, a preoccupation "with a desire to be thinner" and a preoccupation "with the thought of having fat" on one's body. Secondly, within the 170-item questionnaire, all of these subjects acknowledged a fear of becoming fat.

\section{BULIMIA NERVOSA}

Of the remaining 601 respondents, $499(83.0 \%)$ fulfilled the three diagnostic criteria for bulimia nervosa described earlier. The presence of a morbid fear of fatness was assessed in the same manner as before. Again additional checks were made: $91 \%$ responded affirmatively to the two related questions on the eating attitudes test; and the entire group acknowledged a fear of fatness on the 170-item questionnaire. All were women, of whom $20.7 \%$ were married, $5.1 \%$ were housewives, $24.8 \%$ were students or at school, and $12.9 \%$ were in medical or paramedical professions. Only $3.4 \%$ of women were in foodrelated professions.

Age of sample-The mean age of the group was 23.8 years (standard deviation $=5 \cdot 5$ ). As shown in table I most women were in their $20 \mathrm{~s}$ $(67.5 \%)$, none were aged under 15 ; and only $4.6 \%$ were aged over 34 years.

Onset of binge-eating and vomiting-A binge was defined as "an episode of gross overeating which was totally beyond your control." The mean age at onset of binge-eating was 18.4 years (standard deviation 4.5) (table I). Most had begun to eat in binges in their late

TABLE I-Percentage of women in different age groups at onset of binge-eating and of self-induced vomiting

\begin{tabular}{llcccccc}
\hline & \multicolumn{7}{c}{ Age (years) } \\
\cline { 2 - 8 } & $<10$ & $10-14$ & $15-19$ & $20-24$ & $25-29$ & $30-34$ & $>35$ \\
\hline Present age & 0 & 0 & 19.5 & $46 \cdot 0$ & 21.5 & 8.4 & 4.6 \\
Onset of binge-eating & 1.3 & $10 \cdot 5$ & $58 \cdot 3$ & 22.8 & $4 \cdot 3$ & 1.3 & 1.5 \\
Onset of vomiting & 0.2 & 5.7 & 57.2 & 27.0 & 6.3 & 1.6 & 2.0 \\
\hline
\end{tabular}

teens $(58.3 \%)$. The mean duration of binge-eating was 5.2 years (standard deviation 4.7). The onset of vomiting occurred on average almost one year after the onset of binge-eating, the mean age at onset being 19.3 years (standard deviation 4.6). The mean duration of vomiting was 4.5 years (standard deviation 4.0 ). Most women $(83.0 \%$ of the 499$)$ were attempting to lose weight at the time of onset of vomiting; their mean weight at onset was $59.7 \mathrm{~kg}$ (standard deviation 8.8 ) or $103 \%$ of matched population mean weight. In half $(52.7 \%)$ self-induced vomiting was their own idea, but $26 \cdot 6 \%$ got the idea from the media and $17.4 \%$ from friends or relatives.

Frequency of binge-eating and self-induced vomiting-The frequency of binge-eating episodes varied: $27 \cdot 2 \%$ of women reported bingeeating at least once daily, and a further $32.6 \%$ ate in binges at least once weekly. The food eaten during these episodes tended to be of the type avoided at other times. The frequency of vomiting was higher than that of binge-eating: $56.1 \%$ reported vomiting at least once daily and a further $17.5 \%$ more than once weekly. Most women $(67.0 \%)$ vomited by inducing the gag reflex with their fingers, although $15.3 \%$ were able to regurgitate food spontaneously. The vomiting was highly secretive: $\mathbf{3 8 . 7 \%}$ reported total secrecy, and a further $47 \cdot 1 \%$ indicated that less than four people were aware of their behaviour. Some used other methods in addition to vomiting to compensate for their overeating; the most common were exercise $(61.3 \%)$ and the abuse of purgatives $(18.8 \%)$.

Weight history-Of the sample, $83 \cdot 2 \%$ currently weighed between
$85 \%$ and $115 \%$ matched population mean weight; the mean weight was $97.6 \%$ (table II). The weight history suggested that these individuals were prone to being overweight; $45.2 \%$ of women reported a highest weight since menarche of over $115 \%$ (the mean highest weight was $116.2 \%$ ) and $29.7 \%$ had weighed over $120 \%$ (not shown in table II). $43 \%$ reported a lowest weight of less than $85 \%$ (the mean lowest weight since menarche was $86.7 \%$ ) indicating that fewer than half ever had a sufficiently low weight to fulfill current accepted diagnostic criteria for anorexia nervosa. It is interesting to note that $63.2 \%$ would have liked to weigh less than $85 \%$; the average desired weight was $88 \%$ matched population mean weight.

TABLE II-Percentages of women in different weight groups at highest and lowest weights since menarche, ${ }^{*}$ and desired weight

\begin{tabular}{lccccr}
\hline & \multicolumn{5}{c}{$\%$ Of matched population mean weight ${ }^{\circ}$} \\
\cline { 2 - 6 } & $<75$ & $75-85$ & $86-100$ & $101-115$ & $>115$ \\
\hline Present weight $(\%)$ & $1 \cdot 0$ & $10 \cdot 5$ & $54 \cdot 0$ & $29 \cdot 2$ & $5 \cdot 5$ \\
Highest weight since menarche $(\%)$ & $0 \cdot 2$ & $0 \cdot 0$ & $9 \cdot 7$ & $44 \cdot 8$ & $45 \cdot 2$ \\
Lowest weight since menarche $(\%)$ & 12.4 & $30 \cdot 6$ & $50 \cdot 3$ & $6 \cdot 4$ & $0 \cdot 2$ \\
Desired weight $(\%)$ & $11 \cdot 2$ & $52 \cdot 0$ & $36 \cdot 9$ & 0 & 0 \\
\hline
\end{tabular}

${ }^{*}$ Mean age at menarche $13 \cdot 2$ years (SD 1.5).

Menstruation-Despite the fact that most women were within the normal weight range, only $53.4 \%$ had been menstruating regularly during the preceding six months; $39.7 \%$ were menstruating irregularly, and $6.9 \%$ reported amenorrhoea.

Psychopathology-Although all these women had a morbid fear of fatness (by definition) a few (6.9\%) did not admit to having an eating problem. For most women $(63 \%)$ the most pressing complaint was of having lost control over eating. Although most women were of normal weight, $60 \cdot 2 \%$ thought that they were well over the appropriate weight for their height and age, and virtually all (95.6\%) reported that they persistently felt fat. Furthermore, $81.9 \%$ had an intense preoccupation with food and eating, such that their concentration and everyday activities were impaired, and $89.0 \%$ had a score over 30 on the Eating Attitudes Test (mean 49.8, standard deviation 16.3), indicating that the attitudes and behaviour thought characteristic of anorexia nervosa were also present in most of these women. On the General Health Questionnaire $68 \cdot 1 \%$ scored above the threshold $(4 / 5)$ (mean score $=10 \cdot 1$, standard deviation 7.9 ), indicating probable psychiatric disorder ${ }^{6}$; the highest scores were on the anxiety and depression scales.

These descriptive statistics do little justice to the intensity of the response to this small request for information. Many women wrote lengthy letters pleading for help, and most of the respondents expressed surprise and relief at knowing that they were not the only ones to practise self-induced vomiting. Over half $(56.4 \%)$ thought they definitely needed medical help to overcome the problem, yet only $2.5 \%$ were currently receiving medical treatment. Surprisingly, of the group who wanted help, fewer than half $(43 \%)$ had ever mentioned the problem to a doctor; of the entire group with bulimia nervosa only $30 \cdot 1 \%$ had done so.

\section{RESPONDENTS NO LONGER VOMITING}

Of the 49 who were no longer practising self-induced vomiting, $15(30.6 \%)$ had vomited only occasionally. There was no clear indication how the remaining 34 who had vomited regularly had overcome the problem. Most thought a combination of factors had been responsible: the most common were divulging the problem to others $(52.9 \%)$, making a determined decision to stop $(52.9 \%)$, and individual psychotherapy or counselling (35.3\%).

\section{Discussion}

The relationship between bulimia nervosa and anorexia nervosa is of considerable clinical and theoretical interest. The nature of the relationship depends on the definition of anorexia nervosa chosen and in particular whether low body weight is considered to be an essential feature. Most authorities view low body weight as a characteristic feature of the condition ${ }^{810} 11$; 
this is reflected in the most widely used diagnostic criteria, those of Russell ${ }^{8}$ in the United Kingdom and those of the American Psychiatric Association ${ }^{12}$ in the United States. Both stipulate self-induced weight loss resulting in low body weight together with amenorrhoea and certain characteristic psychopathological features. Since we wanted to avoid including in the group with bulimia nervosa those individuals who might have had anorexia nervosa, broad diagnostic criteria for anorexia nervosa ${ }^{8}$ were used. Because of this, the group with anorexia nervosa may have been overinclusive, but the number of individuals in the bulimia nervosa group with anorexia nervosa was minimised.

Despite many similarities between anorexia nervosa and bulimia nervosa, the deceit sometimes associated with the former condition is not a feature of patients who present with bulimia nervosa. ${ }^{4}$ In contrast to those with anorexia nervosa, patients with bulimia nervosa are aware that they have an eating disorder and are distressed by their symptoms. ${ }^{1312}$ Once they have divulged the problem to a doctor they are truthful and eager to receive help. ${ }^{4}$ Nevertheless, information obtained solely by self-reporting must be interpreted cautiously, particularly when used to determine clinical diagnoses.

This population may not be typical of those with bulimia nervosa. The respondents were obtained using a magazine with a largely female readership; also those who requested and returned the questionnaires were probably exceptionally disturbed by their use of vomiting to control their weight. Nevertheless, the population detected in this study closely resembles patients with bulimia nervosa attending psychiatric hospitals. ${ }^{1313}$ Both groups may represent an extreme form of the condition, and there may be many other women with less severe and less distressing features of the disorder.

This study confirms that bulimia nervosa may run a chronic course $^{1}$ and that, despite their grossly disturbed eating habits and attitudes, most patients are of normal body weight. ${ }^{4}$ In the present series a history of having been overweight was common. Binge-eating and a history of obesity have been associated in a population of American college students. ${ }^{14}$ Interestingly, among patients with anorexia nervosa those who eat in binges or induce vomiting frequently have a history of obesity, ${ }^{15} 16$ although this was not found in one major study. ${ }^{17}$ Despite the use of broad diagnostic criteria, less than half of the group with bulimia nervosa appeared to have had anorexia nervosa in the past. This is consistent with two recent reports ${ }^{313}$ but is at variance with the series described by Russell. ${ }^{1}$

The presence of irregular menstruation in almost half the sample suggests that abnormal eating habits may disrupt menstrual function irrespective of body weight. This is supported by a recent investigation of patients with anorexia nervosa one year after completing a treatment study ${ }^{18}$; those who were amenorrhoeic despite having a sufficient body weight for menstrual recovery still had disturbed eating habits.

The use of standardised psychiatric measures in this study confirms that women with bulimia nervosa have high levels of anxiety and depression as well as abnormal attitudes to food. ${ }^{1}$ In the present series less than one-third had ever mentioned their eating difficulties to a doctor, although more than half thought they definitely needed medical help. Two likely explanations for this are: firstly, women with bulimia nervosa have pronounced guilt and shame, which is likely to delay their presentation to a doctor; secondly, as the condition has only recently been described and the patients are of normal body weight and appearance, cases may have gone undetected.

We are grateful for the support of Professor M G Gelder and Professor R E Kendell. The data collection and analysis were funded by Edinburgh University Department of Psychiatry and Oxford University Medical Research Fund respectively.

\section{References}

1 Russell G. Bulimia nervosa: an ominous variant of anorexia nervosa. Psychol Med 1979;9:429-48.

${ }^{2}$ Fairburn CG. Self-induced vomiting. F Psychosom Res 1980;24:193-7.

${ }^{3}$ Pyle RL, Mitchell JE, Eckert ED. Bulimia: a report of 34 cases. $\mathcal{F}$ Clin Psychiatry $1981 ; 42: 60-4$.

4 Fairburn CG. Binge-eating and bulimia nervosa. Vol 1. No 4. Welwyn Garden City: SK and F Publications, 1982.

5 Fairburn CG. The place of a cognitive behavioural approach in the management of bulimia. In: Darby PL, Garfinkel PE, Garner DM Coscina DV, eds. Anorexia nervosa. New York: Alan Liss (in press).

6 Goldberg DP, Hillier VF. A scaled version of the General Health Questionnaire. Psychol Med 1979;9:139-45.

7 Garner DM, Garfinkel PE. The Eating Attitudes Test: an index of the symptoms of anorexia nervosa. Psychol Med 1979;9:273-9.

${ }^{8}$ Russell GFM. Anorexia nervosa: its identity as an illness and its treatment. In: Price JH, ed. Modern trends in psychological medicine, vol 2. London: Butterworths, 1970:131-64

9 Geigy. Average weights of adults (Society of Actuaries: build and blood pressure study, Chicago, 1959). Documenta Geigy-Scientific Tables. Manchester: Geigy Pharmaceutics, 1962:623.

10 Crisp AH. Anorexia nervosa: let me be. London: Academic Press, 1980

${ }^{11}$ Dally P, Gomez J. Anorexia nervosa. London: Heinemann, 1979.

12 American Psychiatric Association. Diagnostic and statistical manual of mental disorders, 3rd ed. Washington DC: American Psychiatric Association, 1980.

${ }^{13}$ Fairburn CG. A cognitive behavioural approach to the management of bulimia. Psychol Med 1981;11:707-11.

${ }^{14}$ Halmi KA, Falk JR, Schwartz E. Binge-eating and vomiting: a survey of a college population. Psychol Med 1981;11:697-706.

15 Beumont PJV, George GCW, Smart DE. "Dieters" and "vomiters and purgers" in anorexia nervosa. Psychol Med 1976;6:617-22.

16 Garfinkel PE, Moldofsky H, Garner DM. The heterogeneity of anorexia nervosa: bulimia as a distinct subgroup. Arch Gen Psychiatry 1980; 37:1036-40.

17 Casper RC, Eckert ED, Halmi KA, Goldberg SC, Davis JM. Bulimia: its incidence and clinical importance in patients with anorexia nervosa. Arch Gen Psychiatry 1980;37:1030-5.

${ }^{18}$ Halmi KA, Falk JR. Behavioural and dietary discriminators of menstrual function in anorexia nervosa. In: Darby PL, Garfinkel PE, Garner DM, Coscina DV, eds. Anorexia nervosa. New York: Alan Liss (in press).

(Accepted 26 February 1982)
DRYING MEDICINES-Drying medicines have contrary faculties to these, viz To consume moisture, stop fluxes, and make such parts dry as are slippery, they make the body and members firm, when they are weakened by too much moisture, that so they may perform their proper functions. Yet although the members be strengthened by drying medicines, they have notwithstanding their own proper moisture in them, which ought to be conserved, and not destroyed, for without it they cannot consist: If then this moisture be consumed by using, or rather over use of drying medicines, the members can neither be nourished, nor yet perform their proper actions. Such medicines as are dry in the third degree, being unadvisedly given, hinder the parts of the body they are appropriated to, of their nourishment, and by that means brings them into consumption. Besides, There is a certain moisture in the body of man, which is called radical moisture, which being taken away, the parts must needs die, seeing natural heat and life also consists in it, and this may be done by too frequent use of medicines dry in the fourth degree: And it may be this was the reason of Galen's writing, that things dry in the fourth degree, must of necessity burn; which is an effect of heat, and not of dryness, unless by burning, Galen means consuming the radical moisture. The use then of drying medicines, is only to such bodies, and parts of the body, as abound with moisture, in which observe these rules. 1 . If the moisture be not extreme, let not the medicine be extremely drying. 2. Let it be proper to the part of the body afflicted, for if the liver be afflicted by moisture, and you go about to dry the brain or heart, you may sooner kill than cure. Thus have we briefly spoken of the first qualities of medicines, and in the general only, and but briefly, because we shall always touch upon them in the exposition of the other qualities, in which you must always have an eye to these. (Nicholas Culpeper (1616-54) The Complete Herbal, 1850.) 